\title{
Graduation ceremony at JRC-IRMM of the first graduates of the Euromaster Measurement Science in Chemistry
}

On 26 October 2010, the first international group of 32 students received their European Diploma Supplements (EDS) linked to the Euromaster "Measurement Science in Chemistry" (MSC) at the European Joint Research Centre-Institute for Reference Materials and Measurements (JRC-IRMM) in a solemn award ceremony in the presence of international press.

Chemical and bio-analytical measurements set the foundations for critical decisions throughout the society. Nevertheless, most students in Europe graduating in chemistry enter the job market lacking appropriate knowledge and competence about quality assurance in this area (e.g. linked to ISO/IEC-17025). For this reason, the JRC-IRMM, whose mission is to promote a common and reliable European measurement system in support of EU policies, has fostered since 2005 the creation of such a consortium. It is currently composed of nine universities (www.msc-euromaster.eu) located in seven European countries and new members may apply. It was awarded the "Euromaster" quality label in 2008 by the ECTNA (European Chemistry Thematic Network Association).

The consortium members also systematically exchange experience on how to improve the way they teach analytical sciences. Active learning and project-based learning play an important role in this context especially during the student summer schools and during the "winter gathering" when lecturers meet.

The consortium contributes to invigorating and innovating analytical sciences in Europe. Should you be interested in joining, please contact the current coordinator, Prof. Ewa Bulska from Warsaw University (ebulska@chem.uw. edu.pl).

(Source: http://irmm.jrc.ec.europa.eu/events/Pages/ 1010_euromaster.aspx). 